\title{
Psychotropic Drugs and Glaucoma - A Brief Overview
}

\author{
Dr Subir Bhattacharjee, RMO cum Clinical Tutor, Institute of Psychiatry, IPGME \& R, Kolkata
}

\section{INTRODUCTION}

Glaucoma is a group of diseases that damage the eye's optic nerve and can result in vision loss and blindness. This "silent thief of vision" is the second most common cause ofblindnessworlwide, currently affecting 60 million people with 8.4 million blind, and projected to rise to 80 million by 2020 with 11.2 million blind. ${ }^{1}$ Though various eye pathologiesplay role in this commonest cause of irreversible blindness, various medications, including psychotropic medicines and ECT, can cause secondary glaucoma in susceptible patients. However, with early detection and treatment, one can often protect serious vision loss. This article provides a brief overview of the relationship between glaucoma and psychiatric treatments.

\section{WHAT IS GLAUCOMA?}

Glaucoma is eye pathology, caused by increased intra ocular pressure (IOP), results in optic nerve end cupping and visual field defect, sometime irreversible. Some time to start with it is without any symptom, mostly Open angle Glaucoma (OAG), presents with a chronic course, but Angle closure Glaucoma (ACG) presents with sudden onset severe eye pain, blurred vision, mid-dilated pupil, redness of the eye, and nausea. ${ }^{2}$ Vision loss from glaucoma, once it has occurred, is permanent. ${ }^{2}$

\section{AQUEOUS HUMOR FLOW DYNAMICS}

Increased IOP is caused due to various reasons which affect the normal drainage of Aqueous humor, watery fluid similar to plasma, present in the anterior compartment of eye, serves as a nutrients and hydrostatic cushion to anterior eye structures. Aqueous humor is secreted from the ciliary body, attachment structure of lens to the eye ball. After passing from the posterior chamber to the anterior chamber via papillary opening, It is then drained by the trabecular meshwork to the schlemm's canal and finally to the episcleral veins.IOP depends on the balance between the formation and drainage of aqueous humor.Whenever there is an obstruction to the outflow mechanism, it results in increased intraocular pressure which finally causes optic nerve head cupping and progressive visual field defect, probably by optic nerve axono-plasmic flow obstruction. ${ }^{3}$

\section{CLASSIFICATION : PATHOPHYSIOLOGY}

Glaucoma can be classified into four main groups: open-angle (OAG), acute angle-closure (ACG), secondary and developmental glaucoma. Based on pathophysiology OAG and ACG are the two main types of Glaucoma and is the topic of discussion here. Again those can be of primary type or secondary one, mainly due to inflammation of eye structures and drugs or toxins. In open/wide-angle glaucoma (OAG), flow is reduced through the trabecular meshwork, due to the degeneration and obstruction of the trabecular meshwork, whose original function is to absorb the aqueous humor. Loss of aqueous humor absorption results in increased resistance and thus a chronic, painless buildup of pressure in the eye (IOP). Whereas in ACG, there is obstruction to the outflow of aqueous humor, results in increased IOP. Other than pupillary block, other mechanisms of angle closure include plateau iris, lens-related and posterior segment pathologies such as aqueous misdirection, choroidal effusion or posterior segment tumors behind the lens that cause forward displacement of the lens-iris diaphragm. ${ }^{4}$ 
In secondary glaucoma, due to drugs or toxins, the main pathophysiology hides behind pupillary and anterior structure nerve innervations. Postsynaptic parasympathetic fibers innervate the ciliary muscle and sphincter pupillae muscle. Postsynaptic sympathetic fibers innervate the dilator pupillae muscle. Following table shows various neuroreceptor mechanisms of ciliary and associated muscles of eye.

\section{Table 1 : Showing Various Neuro-receptor Mechanism Causing Glaucoma}

\begin{tabular}{|l|l|}
\hline Alpha1 receptors cause (pupil) & Mydriasis via the pupillary dilator (radial mm.) \\
\hline M3 receptors cause (pupil) & Miosis via pupillary constrictor (sphincter) \\
\hline Ciliary muscles via M3 can cause & (+) Cyclospasm (contraction) and (-) accommodation (relaxation) \\
\hline Beta2 receptors cause & Secretory epithelium of the ciliary body to produce aqueous humour. \\
\hline Alpha1 agonists will cause & Mydriasis (ex. phenylephrine) \\
\hline
\end{tabular}

\section{Table 2 : Showing Various Causes of Secondary Glaucoma}

\section{Causes of Secondary Glaucoma}

Inflammatory glaucoma

- Uveitis of all types

- Fuchs heterochromic iridocyclitis

Phacogenic glaucoma

- Angle-closure glaucoma with mature cataract

- Phacoanaphylactic glaucoma secondary to rupture of lens capsule

- Phacolytic glaucoma due to phacotoxic meshwork blockage

- Subluxation of lens

- Glaucoma secondary to intraocular hemorrhage

- Hyphema

- Hemolytic glaucoma, also known as erythroclastic glaucoma

Traumatic glaucoma

- Angle recession glaucoma: Traumatic recession on anterior chamber angle

- Postsurgical glaucoma

- Aphakic pupillary block

- Ciliary block glaucoma

Neovascular glaucoma

Drug-induced glaucoma

- Corticosteroid induced glaucoma

- Alpha-chymotrypsin glaucoma. Postoperative ocular hypertension from use of alpha chymotrypsin

Glaucoma of miscellaneous origin

- Associated with intraocular tumors

- Associated with retinal detachments

- Secondary to severe chemical burns of the eye

- Associated with essential iris atrophy

- Toxic glaucoma 


\section{Psychotropic Drugs and Glaucoma - A Brief Overview}

\section{RISK FACTORS FOR GLAUCOMA}

There are various risk factors for developing glaucoma, includes increased pressure in the eye, a family history of the condition, migraines, high blood pressure, obesity, old age, female sex, ethnicity. ${ }^{5-}$ ${ }^{7}$ Certain anatomical features can also increase one's risk, these include a thick crystalline lens, plateau iris configuration and narrow irido-corneal angles. ${ }^{8}$

\section{PSYCHOTROPIC MEDICATIONS AND GLAUCOMA}

Drug-induced glaucoma is a form of secondary glaucoma induced by topical and systemic medications.Various psychotropics including antipsychotics, antidepressant, anti epileptics and sedatives may precipitate glaucoma, Angle closure Glaucoma mainly, due to their associated side effects. Though broadly they can be clustered on the basis of their anticholinergic side effects, specific and sometime unknown mechanism plays their role to cause glaucoma. Anticholinergics inhibit parasympathetic nerve impulses by selectively blocking the binding of the neurotransmitter acetylcholine to its receptor in nerve cells. This can cause glaucoma in individuals with narrow anterior chamber angles by dilating the pupil and causing pupillary block. ${ }^{9}, 10$

\section{PSYCHOTROPIC DRUGS CAUSING ACUTE ANGLE CLOSURE GLAUCOMA}

\section{ANTIPSYCHOTICS}

Typical antipsychotics show strong anticholinergic and/orantiadrenergiceffects(suchaschlorpromazine and fluphenazine) cause mydriasis and cycloplegia. Theoretically they might form a risk factor in terms ofangle closure glaucoma (ACG). Oculogyric crisis is a well known acute side effect of mostly typical antipsychotics, known to increase intra ocular pressure. Antipsychotics have a relatively weaker anticholinergic action and lower possibility of inducing ACG than antidepressant. ${ }^{11}$ Among the available antipsychotic agents, perphenazine, trifluperazine, and fluphenazine have been reported to induce ACG.

\section{ANTIDEPRESSANT}

TCA's are the most notorious to cause ACG among anti depressants by their two most common side effects of mydriasis and cycloplegia. While mydriasis causes visual haze and/or myopia, cycloplegia is related to the paretic effect on ciliary muscle. There are also noradrenalin uptake blockage and alpha-adrenergic receptor blockages due to TCA. Gradually tolerance develops to these side effects over time. TCA with more anticholinergic effects, like amitriptyline, imipramine, nortriptyline should be prescribed with caution to old age people who are more prone to develop glaucoma. ${ }^{12-15}$ Possible ocular side effects related to SSRI are mydriasis, increase in intraocular pressure(IOP), glaucoma and oculogyric crisis. ${ }^{16-18}$ Studies showed that in patients, being treated by SSRI, most common reason of leaving the study was the rise of visual impairment. SSRIs such as sertraline, paroxetine, fluoxetine and citalopram specifically cause pupil dilation. There are various serotonin receptors, among them 5 HT-7 is located on sphincter pupil and as a result of activation of adenylate cyclase it causes an increase in c-AMP and muscle relaxation and rise passive mydriasis. ${ }^{19,20}$ Paroxetine, having the strongest noradrenalin (NA) reuptake inhibition, most commonly causes ACG amongst all SSRI. ${ }^{16}$

SNRI's like venlafaxine, having noradrenergic effects with sympathomimetic effects, have propensity to cause active mydriasis. Adding to the serotonergic effect this may precipitate acute ACG. ${ }^{21}$ In one Pub Med survey, 11 articles are stated reporting the glaucoma in relation with SSRI. While 6 of these are related with paroxetine, 2 are citalopram, one is escitalopram, one is Fluoexetine, one is Fluvoxamine. Most of the cases were in old age patients. No case of glaucoma was reported with sertraline in that survey. ${ }^{22-24}$ The case of escitalopram, a 41 year old woman, is caused due to rotation in anterior chamber 
angle resulting in obstruction of uveal effusion and development of acute bilateral ACG. Stoppage of escitalopram and prompt steroid therapy relieved symptoms of glaucoma. ${ }^{24}$ Both experimental studies and one case report have shown that fluoxetine might cause a significant IOP increase both in animals and in human individual. ${ }^{25}$ Like fluoxetine, fluvoxamine was also reported to cause ACG, which disappeared after stoppage of drug. ${ }^{26}$ In report of "Australian Adverse Drug Reaction Bulletin of February 2001" 11 glaucoma attacks were reported with SSRI. Three of the cases were associated with fluoextine and paroxetine, 4 with sertraline and 1 with citalopram. The age of the patients varied between 32-70 years, most of them were asymptomatic and the cases were detected during routine examination. ${ }^{27}$

\section{ANTIEPILEPTIC}

Topiramate, the most notorious antiepileptic medication, was reported to causes angle-closure glaucoma via ciliary body rotation. It causes idiosyncratic glaucoma, characterized by swelling of the ciliary body and lens due to the relaxation of the zonules and anterior rotation of the lensiris diaphragm causing shallow anteriorchamber, and bilateral angle-closure glaucoma (ACG). The mechanism of topiramate-induced ACG does not involve pupillary block. ${ }^{28}$ Ocular dystonia related to carbamazepine, an antiepileptic, was reported several times in ophthalmic and neurological journals. ${ }^{29}$

\section{BENZODIAZEPINES}

Though only one case of glaucoma was reported with diazepam, benzodiazepines are to be used with caution in glaucoma. ${ }^{30}$

\section{ELECTROCONVULSIVE THERAPY (ECT)}

ECT was reported to increase IOP up to 25-68 $\mathrm{mm} \mathrm{Hg} .{ }^{31-33} \mathrm{ECT}$, itself increases IOP by increasing cerebral blood flow and venous pressure and by increase in extraocular muscle spasm, while anesthetic medications also play role in increasing
IOP by themselves. Succinylcholine, a depolarizing muscle relaxant, can raise IOP, whereas other agents (barbiturates, benzodiazepine, and propofol) can lower it. ${ }^{34}$ Glycopyrrolate causes increase in IOP and results in ACG by pupillary dilatation in susceptible individuals, specifically those with narrow angles. ${ }^{35}$

\section{CONCLUSION}

Glaucoma is a state of raised intra ocular pressure (IOP), can cause blindness if left untreated. Angle Closure Glaucoma (ACG) is caused by papillary block or by obstruction to aqueous humor outflow to the trabecular meshwork. Various drugs including psychotropics can cause ACG due to their side effects, mainly anticholinergic, causing papillary block. ECT and associated anesthetic medications can also precipitate ACG. Susceptible individuals are elders, obese, female patients with family history of glaucoma. Antidepressant, mostly TCA and SSRI, were reported to cause ACG. Typical antipsychotics also were reported. Topiramate precipitates glaucoma by idiosyncratic mechanism. Early detection and stoppage of medications can resolve glaucoma and save vision.

\section{REFERENCES}

1. Quigley HA, Broman AT (2006) The number of people with glaucoma worldwide in 2010 and 2020. Br J Ophthalmol, 90, 262-267.

2. Mantravadi, AV; Vadhar, N (September 2015). "Glaucoma.". Primary care. 42 (3) : 437-49

3. Goel, Manik. "Aqueous Humor Dynamics : A Review". The Open Ophthalmology Journal. 4 (1) : 52-59.

4. Mozaffarieh M, Grieshaber MC, Flammer J. "Oxygen and blood flow : players in the pathogenesis of glaucoma". Mol Vis, 2008; $14: 224-33$

5. Wang L, Zhang X, Cai S, Ma J, Liu X, Wang N. Correlated or not: Glaucoma prevalence and modern industrialization. Med Hypotheses. 2011; 76(2) : 220-224.

6. Tarongoy P, Ho CL, Walton DS. Angle-closure glaucoma $:$ the role of the lens in the pathogenesis, prevention, and treatment. Surv Ophthalmol. 2009; 54(2) : 211-225.

7. Kavitha S, Zebardast N, Palaniswamy K, Wojciechowski R, Chan ES, Friedman DS, Venkatesh R, Ramulu PY. Family history is a strong risk factor for prevalent angle closure in a South Indian population. Ophthalmology. 2014 Nov; 121(11) : 2091-2097.

8. Lai JS, Gangwani RA. Medication-induced acute angle closure attack. Hong Kong Med J. 2012; 18(2) : 139-145 


\section{Psychotropic Drugs and Glaucoma - A Brief Overview}

9. Reid WH, Blouin P. Outpatient psychiatric medications and glaucoma. Psychosomatics. 1976; 17(2) 83-85.

10. Richa S, Yazbek J. Ocular adverse effects of common psychotropic agents: a review. CNS Drugs. 2010; 24(6) : 501-526.

11. Edler K, Gottfries CG, Haslund J, Ravn J. Eye changes in connection with neuroleptic treatment especially concerning phenothiazines and thioxanthenes. ActaPsychiatr Scand. $1971 ; 47: 377-84$

12. Lieberman E, Stoudemire A. Use of tricyclic antidepressants in patients with glaucoma : assessment and appropriate precautions. Psychosomatics. 1987; 28 : 145-8.

13. Shur E, Checkley S. Pupil studies in depressed patients : an investigation of the mechanism of action of desipramine. Br J Psychiatry. 1982; 140 : 181-4.

14. Ritch R, Krupin T, Henry C, Kurata F. Oral imipramine and acute angle closure glaucoma. Arch Ophthalmol. 1994; 112 : $67-8$.

15. Lowe RF. Amitriptyline and glaucoma. Med J Aust. 1966; 2 : 509-10.

16. Costagliola C, Parmeggiani F, Sebastiani A. SSRIs and intraocular pressure modifications: evidence, therapeutic implications and possible mechanisms. CNS Drugs. 2004; $18: 475-84$.

17. Patel OP, Simon MR. Oculogyric dystonic reaction to escitalopram with features of anaphylaxis including response to epinephrine. Int Arch Allergy Immunol. 2006; $140: 27-29$.

18. Schmitt JA, Riedel WJ, Vuurman EF, Kruizinga M, Ramaekers JG. Modulation of the critical flicker fusion effects of serotonin reuptake inhibitors by concomitant pupillary changes. Psychopharmacology (Berl). 2002; 160 : 381-6.

19. Deijen JB, Loriaux SM, Orlebeke JF, et al. Effects of paroxetine and maprotiline on mood, perceptual-motor skills and eye movements in healthy volunteers. J Psychopharmacol. 1989; $3: 148-55$.

20. Ramaekers JG, Muntjewerff ND, O'Hanlon JF. A comparative study of acute and subchronic effects of dothiepin, fluoxetine and placebo on psychomotor and actual driving performance. Br J ClinPharmacol. 1995; 39 : 397-404.

21. Costagliola C, Mastropasqua L, Capone D, Verolino M, Ciancaglini M, Pisanti N. Effect of fluoxetine on intraocular pressure in the rabbit. Exp Eye Res. 2000; 70 : 551-5.
22. Croos R, Thirumalai S, Hassan S, Davis Jda R. Citalopram associated with acute angle-closure glaucoma : case report [letter]. BMC Ophthalmol. 2005; 5 : 23.

23. Massaoutis P, Goh D, Foster PJ. Bilateral symptomatic angle closure associated with a regular dose of citalopram, an SSRI antidepressant. Br J Ophthalmol. 2007; 91 : 1086-7.

24. Zelefsky JR, Fine HF, Rubinstein VJ, Hsu IS, Finger PT. Escitalopraminduced effusions and bilateral angle closure glaucoma. Am J Ophthalmol. 2006; 141 : 1144-7.

25. Costagliola C, Mastropasqua L, Steardo L, Testa N. Fluoxetine oral administration increases intraocular pressure [letter]. Br J Ophthalmol. 1996;80:678.

26. Jimenez-Jimenez FJ, Orti-Pareja M, Zurdo JM. Aggravation of glaucoma with fluvoxamine. Ann Pharmacother. 2001; 35 : 1565-6.

27. Adverse Drug Reactions Advisory Committee (ADRAC). SSRIs and increased intraocular pressure [abstract]. Aust Adv Drugs Reac Bull. 2001; 20 : 3.

28. Acharya N, Nithyanandam S, Kamat S. Topiramateassociated bilateral anterior uveitis and angle closure glaucoma. Indian J Ophthalmol. 2010; 58(6) : 557-559.

29. Berchou RC, Rodin EA. Carbamazepine-induced oculogyric crisis. Arch Neurol. 1979; 36 : 522-3.

30. Hyams SW, Keroub C. Glaucoma due to diazepam. Am J Psychiatry 1997; 134 : 447-8.

31. Edwards RM, Stoudemore A, Vela MA, Morris R. Intraocular pressure changes in nonglaucomatous patients undergoing electroconvulsive therapy. Convulse Ther. 1990; $6: 209-213$.

32. Epstein H, Fagman W, Bruce DL, Abram A. Intraocular pressure changes during anesthesia for electroshock therapy. AnesthAnalg. 1975; $54:$ 479-481.

33. Ottoso JO, Rendahl I. Intraocular pressure in electroconvulsive therapy. Arch Ophtahlmol. 1963; 70 : 264-265.

34. Edwards RM, Stoudemore A, Vela MA, Morris R. Intraocular pressure changes in nonglaucomatous patients undergoing electroconvulsive therapy. Convulse Ther. 1990; 6 : 209-213.

35. Van Den Berg AA, Honjol NM. Electroconvulsive therapy and intraocular pressure. Middle East J Anesthesiol. 1998; 14(4) : 249-258. 